\title{
ACTA AGRONOMICA \\ HUNGARICA
}

\section{AN INTERNATIONAL MULTIDISCIPLINARY JOURNAL IN AGRICULTURAL SCIENCES}

Acta Agronomica Hungarica publishes original papers, short communications, review articles and book reviews of international interest in the field of basic and applied research in agronomy

Acta Agronomica Hungarica is published in yearly volumes of four issues by

$$
\text { AKADÉMIAI KIADÓ }
$$

H-1117 Budapest, Prielle K. u. 4, Hungary http://www.akkrt.hu

Manuscripts and editorial correspondence should be addressed to

Prof. József Sutka

Acta Agronomica Hungarica

Agricultural Research Institute of the

Hungarian Academy of Sciences

H-2462 Martonvásár, Hungary

Phone: (36-22) 569-500

Fax: (36-22) 460-213

E-mail: actaagr@fsnew.mgki.hu

Subscription information

Orders should be addressed to

AKADÉMIAI KIADÓ

H-1519 Budapest, P. O. Box 245, Hungary

Fax: (36-1) 464-8221

E-mail: kiss.s@akkrt.hu

Subscription price for Volume 47 (1999) in 4 issues US\$ 170.00 including normal postage, airmail delivery US $\$ 20.00$

HU ISSN 0238-0161 